\title{
PHYTOCHEMICAL CHARACTERIZATION OF TRANSILVANIAN PRUNELLA VULGARIS
}

\author{
Alexandra GROȘAN ${ }^{1}$, Ruxandra ȘTEFĂNESCU²*, Camil-Eugen VARI ${ }^{1}$, George JÎTCĂ ${ }^{1}$, \\ Mădălina BĂTRÂNU ${ }^{3}$, Lucia Daniela MUNTEAN ${ }^{4}$
}

\author{
${ }^{1}$ Department of Pharmacology and Clinical Pharmacy, Faculty of Pharmacy, George Emil Palade University \\ of Medicine, Pharmacy, Science and Technology of Târgu Mureș, Romania \\ ${ }^{2}$ Discipline of Pharmacognosy and Phytotherapy, Faculty of Pharmacy, George Emil Palade University of \\ Medicine, Pharmacy, Science and Technology of Târgu Mureș, Romania \\ ${ }^{3}$ Faculty of Pharmacy, George Emil Palade University of Medicine, Pharmacy, Science and Technology of \\ Târgu Mureș, Romania \\ ${ }^{4}$ Department of Analytical Chemistry and Drug Analysis, Faculty of Pharmacy, George Emil Palade \\ University of Medicine, Pharmacy, Science and Technology of Târgu Mureș, Romania
}

\author{
*Correspondence: \\ Ruxandra ȘTEFĂNESCU \\ ruxandra.braic@yahoo.com,ruxandra.stefanescu@umfst.ro
}

Received: 22 April 2020; Accepted: 09 June 2020; Published: 30 June 2020

\begin{abstract}
Prunella vulgaris L. grows in spontaneous flora of Romania in wet places, fields, meadows, unpopulated areas, both in the sun and in the shade. The plant is rich in phenolic acids (caffeic acid, rosmarinic acid), pentacyclic triterpenic compounds (ursolic, oleanolic, betulinic acid) and flavonoids (rutoside, quercetin). Prunella vulgaris L. has shown numerous pharmacological actions: antioxidant, antiallergic, antimicrobial, immunostimulatory activities. The aim of the study was to evaluate the phytochemical and pharmacological profile of the leaves and spike inflorescence of Prunella vulgaris L. collected from Romania. The polyphenol content in leaves was found to be $63.78 \pm 2.01 \mathrm{mg}$ GAE/g dry weight in the methanolic extract and $45.73 \pm 13.87 \mathrm{mg} \mathrm{GAE} / \mathrm{g}$ in the aqueous extract. In the spike inflorescence, total polyphenol content was $36.44 \pm 6.73 \mathrm{mg} \mathrm{GAE} / \mathrm{g}$ in the methanolic extract and $26.49 \pm$ $2.97 \mathrm{mg} \mathrm{GAE} / \mathrm{g}$ in the aqueous extract. The results from the antioxidant assays (DPPH and ABTS) were not significantly different between the two herbal drugs. Further studies are needed in order to quantify the active compounds.
\end{abstract}

Keywords: Prunella vulgaris, total polyphenols, antioxidant, Lamiaceae.

\section{Introduction}

Prunella vulgaris L. (PV) is one of the herbs having a long history of traditional use in Chinese medicine (Pinkas, 1994). According to the empirical evidence, the infusion of Prunella vulgaris $\mathrm{L}$. was used to treat diseases of the mouth, migraines, skin conditions (Zdařilová et al., 2009; Vostálová et al., 2010; Sârbu et al., 2013). It has a monography in the latest edition of the European Pharmacopoeia (Eur. Ph. 8.0, 2011). Prunellae spica represents an important source of active compounds: phenolic acids, flavonoids, pentacyclic triterpenic compounds, 
sterols and polysaccharides (Morteza-Semnani et al., 2006; Mahboubi et al., 2015). According to the published reports, there is a direct correlation between the concentration of phenolic compounds in herbal drugs and their antioxidant activity (Shan et al., 2005). Medicinal properties attributed to Prunella sp. include anti-allergic, anti-inflammatory (Ryu et al., 2000), immunostimulatory (Han et al., 2009; Hwang et al., 2013a), antihyperglycemic (Zheng et al., 2007), and antihypertensive (Fu et al., 2011). Ethanolic and aqueous extracts of the species induce apoptosis, thus having a link between antioxidant action and phenolic content (Hwang et al., 2013b). Also, the literature indicates that the extracts exhibit antiviral and antimicrobial actions (Komal et al., 2018; Li et al., 2019). Prunella vulgaris can be found in the wild flora of Romania, but there is a lack of information regarding the phytochemical profile of the herbal drug. Being a widespread species in Romania, the defined objectives of the present study are the analysis of the plant product by chromatographic methods and the evaluation of the antioxidant action. Because most of the natural treatments indicate the preparation of plants as an infusion, a study of the Prunella vulgaris species is required for a comparative analysis depending on the extraction yield to obtain an extract with the richest concentration in active principles.

\section{Materials and Methods}

\section{Plant material}

Prunella vulgaris L. leaves and spike inflorescence were harvested from Mureș County, Romania. Harvesting was done at the end of the flowering period, when the fruit develops, in August. The herbal drug was dried in the shade and kept in laboratory conditions until analysis. Voucher specimens of all samples (PV-L-19, PV-SI-19) are deposited at the Department of Pharmacognosy and
Phytotherapy, Faculty of Pharmacy, George Emil Palade University of Medicine, Pharmacy, Science, and Technology of Târgu Mureș, Romania.

\section{Preparation of PV extracts}

Aqueous extract (PV-AQ): $5 \mathrm{~g}$ of dried and crushed plant product (leaf (L) or spike inflorescence (SI)) were extracted with $50 \mathrm{~mL}$ of distilled water for one hour at $60{ }^{\circ} \mathrm{C}$ on an ultrasonic water bath followed by filtration.

Methanolic Extract (PV-Me): $5 \mathrm{~g}$ of dried and crushed plant product (leaf - L or spike inflorescence - SI) were extracted with $50 \mathrm{~mL}$ methanolic solution $(70: 30 v / v$, methanol: water) for one hour at $60{ }^{\circ} \mathrm{C}$ on an ultrasonic water bath followed by filtration.

\section{Thin-layer chromatography (TLC)}

The solutions $(30 \mu \mathrm{L}$ of the methanolic extract from spike inflorescence) were spotted on TLC silicagel plates (ALUGRAM Xtra SIL G Macherey- Nagel Düren, 10 x 20) as $1 \mathrm{~cm}$ bands, using a Hamilton syringe. Plates were developed in an ascending mode in a saturated chamber using ethyl acetate-methanol-water (40:5.4:4, $v / v / v)$ as a mobile phase. Rosmarinic acid, caffeic acid, betulinic acid, quercetin, rutozide were used as standards. Following development, the plates were dried and spayed with diphenylboroyloxymethylamine and PEG $4005 \%$ solution in $\mathrm{MeOH}$ for fluorescence intensification and stabilization. The chromatograms were observed in UV/Vis before and after pulverization. An UV lamp 254/365nm Vilber Lourmat was used for compounds identification at $365 \mathrm{~nm}$.

\section{Total polyphenol content (TPC)}

The total polyphenol content was determined spectrophotometrically using Folin Ciocalteu reagent (Singleton et al., 1999). A standard curve for gallic acid was prepared with five points ranged between 0.002-0.02 
$\mathrm{mg} / \mathrm{mL}\left(\mathrm{R}^{2}=0.9865\right)$. The results were expressed as mg of gallic acid equivalents/ $1 \mathrm{~g}$ of the dried herbal drug.

\section{DPPH radical scavenging activity}

Free radical scavenging activity was performed using DPPH method. To $2,5 \mathrm{~mL}$ methanol solution of DPPH $0,1 \mathrm{mM}$, different volumes of samples $(50 \mu \mathrm{L}, 100 \mu \mathrm{L}, 200 \mu \mathrm{L}$, $300 \mu \mathrm{L}, 400 \mu \mathrm{L}, 500 \mu \mathrm{L})$ were added. The absorbance was measured at $517 \mathrm{~nm}$ (using a UV-VIS spectrophotometer) after 30 minutes. The $\%$ inhibition was calculated using the following formula:

$\%$ inhibition $=[($ A control - A sample $) /(\mathrm{A}$ control)]*100

The $\mathrm{IC}_{50}$ (the concentration of the sample that scavenge $50 \%$ of DPPH free radical) values were determined. Ascorbic acid was used as positive control (Shen et al., 2010; Fazal et al., 2016; Nayak et al., 2018).

\section{ABTS radical scavenging activity}

The $\mathrm{ABTS}^{\cdot+}$ radical cation was generated by reacting $10 \mathrm{mg}$ ABTS and $2.45 \mathrm{mM}$ potassium persulfate, followed by incubation at room temperature, in the dark for 12 hours. The $\mathrm{ABTS}^{\cdot+}$ solution was diluted with ethanol. To $2.5 \mathrm{~mL} \mathrm{ABTS}^{\cdot+}$ solution, different extract volumes $(10 \mu \mathrm{L}, 60 \mu \mathrm{L}, 90 \mu \mathrm{L}, 150 \mu \mathrm{L}, 300$ $\mu \mathrm{L}$ )were added and the absorbance was measured after 6 minutes at $734 \mathrm{~nm}$ (using a UV-VIS spectrophotometer). The controls contained the extraction solvent instead of the test sample. The \% inhibition was calculated using the following formula: $\%$ inhibition $=[(\mathrm{A}$ control - A sample) / (A control) $]^{*} 100$, where $\mathrm{A} 0$ is the absorbance of the control and A1 is the absorbance of the test samples.

Results were expressed as $\mathrm{IC}_{50}(\mu \mathrm{g} / \mathrm{mL})$. Ascorbic acid was used as positive control (Zheleva-Dimitrova et al., 2010; Chew et al., 2011).

\section{Data analysis}

Statistical analysis was performed using Graph Pad Prism 8. All measurements were made in triplicate, and the results were expressed as mean \pm SD. Analysis of variance (ANOVA) was performed, followed by Tukey's multiple comparison Test at $p<0.05$.

\section{Results and discussions}

Qualitative TLC analysis was performed in order to identify the main polyphenolic compounds found in the Prunella inflorescence. TLC is widely used in quality control of natural products and food supplements, as the procedure is a rapid, cheap and straightforward method. TLC of sample and reference compounds were analyzed before and after spraying, in daylight, and at $\mathrm{UV}_{365}$ $\mathrm{nm}$. Before revelation, two yellow spots were observed, corresponding to the 2 flavonoids used as standard compounds: rutozide $(\mathrm{Rf}=$ $0.9)$ and quercetin $(\mathrm{Rf}=0.26)$. After revelation with NEU reagent, in daylight, yellow-green spots corresponding to rosmarinic acid were observed, yellow-colored spots corresponding to rutozide and caffeic acid. In UV light (Fig. 1), polyphenolic compounds with specific fluorescence are observed. In Prunellae spica extracts, rosmarinic acid $(\mathrm{Rf}=0.28)$ with greenish-blue fluorescence was identified on the basis of the retention factor, in comparison with the reference compounds used. Analyzing the chromatographic plate, we can observe that rosmarinic acid is the major compound considering the intensity of the spot. The presence of an orange spot was also observed, indicating the presence of a flavonozide. Due to the fact that caffeic acid and betulinic acid had the same retention factor using this mobile phase, it is not possible to determine which of these compounds are present in the extract. 


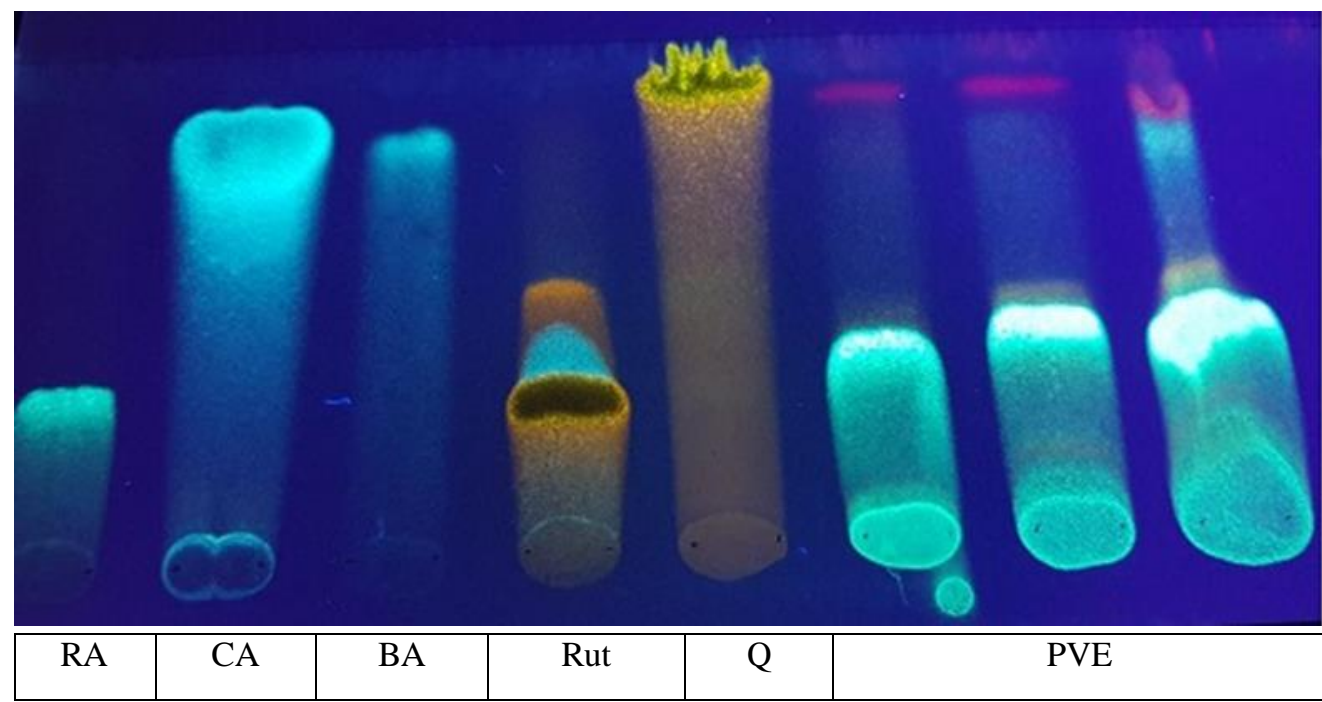

Fig. 1. Chromatograms of Prunella vulgaris inflorescence extract after spraying with NEU / PEG reagent, in UV $365 \mathrm{~nm}$. From left to right: rosmarinic acid, caffeic acid, betulinic acid, rutozide, quercetin, Prunella vulgaris extracts

Although the TLC analysis offers only qualitative information, we can conclude that the main polyphenolic compound found in Prunella vulgaris flowers is rosmarinic acid. The results are consistent with the reported data (Shekarchi et al., 2012; Wagner et al., 2016).

The methanol extract of Prunellae spica are characterized in the upper $\mathrm{Rf}$ range by rosmarinic acid - $\mathrm{RA}(\mathrm{Rf}=0.28)$, caffeic acid CA ( $\mathrm{Rf}=0.8)$, betulinic acid - BA $(\mathrm{Rf}=0.8)$, rutozide - Rut ( $\mathrm{Rf}=0.26)$, quercetin - $\mathrm{Q}$ ( $\mathrm{Rf}=0.9)$ (Fig. 1).

Polyphenols are plant secondary metabolites, considered to be a valuable class of natural compounds with a highly satisfactory therapeutic effect.

Many researches aiming to characterize the spike of Prunella vulgaris have been published in recent years in China and other countries, however, the herbal drug collected from Romania is poorly characterized (Collins et al., 2009; Liu et al., 2017).

Our results are very similar to the results obtained by Aybastier et al. (2011) with the plant collected from Turkey. Although most researches were focused on the extracts obtained from PV spike, the TPC was significant higher in the extracts obtained from the leaves. The moment of harvesting is probably responsible for the lower quantity of polyphenols in the spike. It is known that the content of secondary metabolites (rosmarinic acid, caffeic acid) in herbal drugs varies considerably through the plant development and subsequently their antioxidant action depends on the moment of harvest (Chen et al., 2019). We have chosen to collect the herbal drug at the end of the flowering period, when the fruit develops, because Prunella vulgaris fruits contain mainly oleanolic and usolic acids (Du and Chen, 2009). These pentacyclic triterpenic acids are known to have great pharmacological actions like anti-diabetic, antihyperlipidemic, antiinflamatory and hepatoprotective effects (Kashyap et al., 2016; Ayeleso et al., 2017; Ding et al., 2018). The extraction solvent plays an important role regarding the final concentrations of active principles in the obtained extracts. As an extraction solvent, methanol is often used because it assures high extraction yields than other polar solvents. 
Table 1. TPC and antioxidant activity

\begin{tabular}{|l|l|l|l|}
\hline Sample & TPC $(\mathbf{m g}$ GAE $/ \mathbf{g}$ DW $)$ & $\begin{array}{l}\text { DPPH } \\
\mathbf{I C}_{\mathbf{5 0}}(\boldsymbol{\mu} \mathbf{g} / \mathbf{m L})\end{array}$ & $\begin{array}{l}\text { ABTS } \\
\mathbf{I C}_{\mathbf{5 0}}(\boldsymbol{\mu} \mathbf{g} / \mathbf{m L})\end{array}$ \\
\hline PV - L - MeOH & $63.78 \pm 2.01^{\mathrm{a}}$ & $35.31 \pm 0.68$ & $1.29 \pm 0.12$ \\
\hline PV - L - AQ & $45.73 \pm 13.87^{\mathrm{ab}}$ & $61.35 \pm 0.99$ & $2.23 \pm 0.11$ \\
\hline PV - SI - MeOH & $36.44 \pm 6.73^{\mathrm{b}}$ & $53.89 \pm 4.93$ & $1.53 \pm 0.11$ \\
\hline PV - SI - AQ & $26.49 \pm 2.97^{\mathrm{b}}$ & $56.64 \pm 2.81$ & $2.32 \pm 0.15$ \\
\hline
\end{tabular}

DW - dry weight of the herbal drug; all tests were performed in triplicate; different letters in columns mean statistically significant differences

For an optimal extraction of polyphenolic compounds, studies have revealed that the percentage of methanol should be varied between 50\% and 80\% (Gupta, 2010).

Our findings (Table 1) are in line with data from earlier studies. TPC values measured for Prunella vulgaris extracts varied has been reported to be between $8.05-63.75 \mathrm{mg} \mathrm{GAE} \mathrm{/}$ g dry plant (Aybastier et al., 2011; Singh et al., 2015; Chen et al., 2019; Shanaida et al., 2018). TPC was expressed in $\mathrm{mg}$ GAE/g DW, all of the determinations being made three times. Dosing total polyphenols at an early stage of the study is important because there are numerous studies that compare the antioxidant action to biological activity (Mahboubi et al., 2015). Although the concentration of polyphenolic compounds is higher in the methanolic extracts, our study revealed that there are no significant differences (at $\mathrm{p}<0.05$ ) between methanolic and aqueous extracts from the same herbal drug. The main criteria underlying solvent selection are its yield and toxicity. In a study carried out in Iran, the TPC from the dried parts of Prunella vulgaris L. species were determined. The results showed that the herbal drug harvested from Iran contains 2 times higher concentrations of total polyphenols (115-156 mg GAE/g) than the product used in the present study (Mahboubi et al., 2015).

The pedo-climateric influence over the phytochemical profile of plants is well documented in the scientific literature. According to Sárosi et al. (2015) the herbal products obtained from Prunella vulgaris that grows in sunny exposure contain higher quantities of polyphenolic compounds than the plants that grow in shade.

The DPPH assay is based on the reduction of DPPH radical, resulting a discoloration of the violet solution. This is a simple and quick method to determine the antioxidant action by means of a suitable dilution of hydroalcoholic extracts of Prunella vulgaris species) (Sochor et al., 2010; Lee et al., 2015).

The ABTS radical scavenging assay is based on the formation of ABTS radical resulting in a blue solution and the subsequent reduction of the cation by the antioxidant compounds, resulting a discoloration of the solution. Feng et al. (2010) demonstrated the antioxidant action of different hydroalcoholic extracts from Prunella vulgaris. Positive correlations between the total polyphenol content and antioxidant activity were reported in their work. We can assume that rosmarinic acid found in high quantities is the main compound responsible for the antioxidant action (Cao et al., 2005). The results obtained in the two radical scavenging assays suggest the scientific basis for its folkloric use in some pathologic conditions.

\section{Conclusions}

On the basis of our results, we can conclude that both herbal drugs obtained from Prunella vulgaris are an important source of polyphenolic compounds with antioxidant 
potential and thus we can continue further researches regarding on the therapeutic potential of this species. Giving the obtained results, we suggest that aqueous extracts may be further used in preclinical studies in order to prevent the toxicity of methanol. Further detailed phytochemical screenings are needed in order to observe the influence of Transylvanian specific pedo-climateric conditions.

\section{Conflict of Interest}

The authors declare that the research was conducted in the absence of any commercial or financial relationships that could be construed as a potential conflict of interest.

\section{Acknowledgments}

This research was supported by a project funded by the Internal Research Grants of the University of Medicine and Pharmacy of Târgu Mureş, Romania (grant contract for execution of research projects nr. 15609/10/29.12.2017).

\section{References}

1. *** Europea Pharmacopeiaea, 8th edition, 2011, pp. 1219-1220.

2. Aybastier Ö, Şahin S, Işik E, Demir C. (2011) Determination of total phenolic content in Prunella L. by horseradish peroxidase immobilized onto chitosan beads. Anal. Methods 3(10):2289-2297. doi: 10.1039/c1ay05218g

3. Ayeleso TB, Matumba MG, Mukwevho E (2017) Oleanolic acid and its derivatives: Biological activities and therapeutic potential in chronic diseases. Molecules 22(11): 1915 .

doi: 10.3390/molecules22111915

4. Cao H, Cheng WX, Li C, Pan XL, Xie XG, Li TH (2005) DFT study on the antioxidant activity of rosmarinic acid. J. Mol. Struct.
THEOCHEM 719:177-183. doi: 10.1016/j.theochem.2005.01.029

5. Chen Y, Zhang X, Guo Q, Cao L, Qin Q, Li C, Zhao M, Wang M (2019) Plant morphology, physiological characteristics, accumulation of secondary metabolites and antioxidant activities of Prunella vulgaris L. under UV solar exclusion. Biol. Res. 52(1):17. doi: 10.1186/s40659-019-0225-8

6. Chew KK, Khoo MZ, Ng SY, Thoo, YY, Aida WW, Ho CW (2011) Effect of ethanol concentration, extraction time and extraction temperature on the recovery of phenolic compounds and antioxidant capacity of Orthosiphon stamineus extracts. International Food Research Journal 18(4):1427.

7. Collins NH, Lessey EC, DuSell CD, McDonnell DP, Fowler L, Palomino WA, Lessey BA (2009) Characterization of antiestrogenic activity of the Chinese herb, Prunella vulgaris, using in vitro and in vivo (Mouse Xenograft) models. Biology of reproduction 80(2):375-383.

8. Ding $\mathrm{H}, \mathrm{Hu} \mathrm{X}, \mathrm{Xu} \mathrm{X}$, Zhang G, Gong D (2018) Inhibitory mechanism of two allosteric inhibitors, oleanolic acid and ursolic acid on $\alpha$-glucosidase. Int. J. Biol. Macromol. 107:1844-1855.

doi: 10.1016/j.ijbiomac.2017.10.040

9. Du H, Chen XQ (2009) A comparative study of the separation of oleanolic acid and ursolic acid in Prunella vulgaris by high-performance liquid chromatography and cyclodextrin-modified micellar electrokinetic chromatography. J. Iran. Chem. Soc. 6(2):334-340. doi: 10.1007/BF03245842

10. Fazal H, Abbasi BH, Ahmad N, Ali SS, Akbar F, Kanwal F (2016) Correlation of different spectral lights with biomass accumulation and production of antioxidant secondary metabolites in callus cultures of medicinally important Prunella vulgaris L. 
Journal of Photochemistry and Photobiology B: Biology 159:1-7.

11. Feng L, Jia X, Zhu MM, Chen Y, Shi F (2010) Antioxidant activities of total phenols of Prunella vulgaris L. in vitro and in tumor-bearing mice. Molecules 15(12):9145-9156. doi: 10.3390/molecules15129145

12. Fu JY, Qian LB, Zhu LG, Te Liang H, Tan YN, Lu HT, Lu JF, Wang HP, Xia Q (2011) Betulinic acid ameliorates endothelium-dependent relaxation in 1NAME-induced hypertensive rats by reducing oxidative stress. Eur. J. Pharm. Sci. 44(3):385-391.

doi: 10.1016/j.ejps.2011.08.025

13. Gupta D (2010) Reactive oxygen species and antioxidants in higher plants. Boca Raton: CRC Press, pp. 333-334.

14. Han EH, Choi JH, Hwang YP, Park HJ, Choi CY, Chung YC, Seo JK, Jeong HG (2009) Immunostimulatory activity of aqueous extract isolated from Prunella vulgaris. Food Chem. Toxicol. 47(1):6269. doi: 10.1016/j.fct.2008.10.010

15. Hwang YJ, Lee EJ, Kim HR, Hwang KA (2013a) In vitro antioxidant and anticancer effects of solvent fractions from Prunella vulgaris var. lilacina. BMC Complement. Altern. Med. 13(1):310. doi: 10.1186/14726882-13-310

16. Hwang YJ, Lee EJ, Kim HR, Hwang KA (2013b) NF-кB-targeted anti-inflammatory activity of Prunella vulgaris var. lilacina in macrophages RAW 264.7. Int. J. Mol. Sci. 14(11):21489-21503. doi: 10.3390/ijms 141121489

17. Kashyap D, Tuli HS, Sharma AK (2016) Ursolic acid (UA): A metabolite with promising therapeutic potential. Life Sci. 146:201-213. doi: $10.1016 /$ j.lfs.2016.01.017

18. Komal S, Kazmi SAJ, Khan JA, Gilani MM (2018) Antimicrobial activity of
Prunella vulgaris extracts against multidrug resistant Escherichia coli from patients of urinary tract infection. Pakistan J. Med. Sci. 34(3):616-620. doi: 10.12669/pjms.343.14982

19. Lee KJ, Oh YC, Cho WK, Ma JY (2015) Antioxidant and anti-inflammatory activity determination of one hundred kinds of pure chemical compounds using offline and online screening HPLC assay. EvidenceBased Complementary and Alternative Medicine, 2015.

20. Li BY, Hu Y, Li J, Shi K, Shen YF, Zhu B, Wang GX (2019) Ursolic acid from Prunella vulgaris L. efficiently inhibits IHNV infection in vitro and in vivo. Virus Res. 273:197741. doi: 10.1016/j.virusres.2019.197741.

21. Liu ZX, Hua YJ, Wang SN, Zou LS, Liu XH, Zhao H, Yan Y (2017) Quality Evaluation of Prunellae Spica Based on Simultaneous Determination of Multiple Bioactive Constituents Combined with Grey Relational Analysis. Natural Product Communications, 12(7). $1934578 X 1701200729$.

22. Mahboubi M, Mahboubi A, Kazempour N (2015) The antimicrobial activity of Prunella vulgaris extracts. Herba Pol. 61(1):31-38. doi: 10.1515/hepo-2015-0008 23. Morteza-Semnani K, Saeedi M, Akbarzadeh M (2006) The essential oil composition of Prunella vulgaris L. J. Essent. Oil-Bearing Plants 9(3):257-260. doi: 10.1080/0972060X.2006.10643500

24. Nayak A, Khan MA, Sharma P, Mishra RM (2018) Phytochemical screening, antioxidant and antimicrobial activities of Prunella vulgaris for oral thrush. Journal of Drug Delivery and Therapeutics 8(5):251258.

25. Pinkas M, Trotin F, Peng W, Torck M (1994) Use, chemistry and pharmacology of 
ten chinese medicinal plants. Fitoterapia 65(4):343-353.

26. Ryu SY, Oak MH, Yoon SK, Cho DI, Yoo GS, Kim TS, Kim KM (2000) Anti-allergic and anti-inflammatory triterpenes from the herb of Prunella vulgaris. Planta Med. 66(4):358-360. doi: 10.1055/s-2000-8531

27. Sârbu I, Ștefan N, Oprea A (2013) Plante Vasculare din România - Determinator ilustrat de teren, Editura Victor B Victor, București 18-22: 650

28. Sárosi S, Bernáth J, Bertoli A, Pistelli L, Burchi G, Antonetti M, Benvenuti S (2015) Effect of different plant origins and climatic conditions on the total phenolic content and total antioxidant capacity of self-heal (Prunella vulgaris L.). Acta Hortic. 925:49-56.

doi: 10.17660/actahortic.2011.925.5

29. Shan B, Cai YZ, Sun M, Corke H (2005) Antioxidant capacity of 26 spice extracts and characterization of their phenolic constituents. J. Agric. Food Chem., 53(20):7749-7759. doi: 10.1021/jf051513y

30. Shanaida M, Golembiovska O, Hudz N, Wieczorek PP (2018) Phenolic compounds of herbal infusions obtained from some species of the Lamiaceae family. Curr. Issues Pharm. Med. Sci. 31(4):194-199. doi: 10.1515/cipms-2018-0036

31. Shekarchi M, Hajimehdipoor H, Saeidnia S, Gohari AR, Hamedani MP (2012) Comparative study of rosmarinic acid content in some plants of Labiatae family. Pharmacognosy magazine, 8(29):37.

32. Shen Q, Zhang B, Xu R, Wang Y, Ding X, Li $P$ (2010) Antioxidant activity in vitro of selenium-contained protein from the seenriched. Bifodobacterium animalis 01. Anaerobe, 16:380-386.

33. Singh MK, Joshi C, Joshi N, Sharma R, Brijwal L, Kumar RS (2015) Scrutinizing the antioxidant potential of Prunella vulgaris L. : A medicinal plant from central
Himalayan region. Int. J. Fundam. Appl. Sci. 4(1):1-8.

34. Singleton VL, Orthofer R, LamuelaRaventos RM (1999) Analysis of total phenols and other oxidation substrates and antioxidants by means of Folin-Ciocalteu reagent. Methods Enzymol. 299(1974):152-178. doi: 10.1016/S00766879(99)99017-1

35. Sochor J, Ryvolova M, Krystofova O, Salas P, Hubalek J, Adam V, Provaznik I (2010) Fully automated spectrometric protocols for determination of antioxidant activity: Advantages and disadvantages. Molecules, 15(12):8618-8640.

36. Vostálová J, Zdařilová A, Svobodová A (2010) Prunella vulgaris extract and rosmarinic acid prevent UVB-induced DNA damage and oxidative stress in HaCaT keratinocytes. Archives of dermatological research, 302(3):171-181.

37. Wagner H, Bauer R, Melchart, D, Staudinger A (2016) Spica PrunellaeXiakucao. In Chromatographic Fingerprint Analysis of Herbal Medicines, 4:225-237.

38. Zdařilová A, Svobodová A, Šimánek V, Ulrichová J (2009) Prunella vulgaris extract and rosmarinic acid suppress lipopolysaccharide-induced alteration in human gingival fibroblasts. Toxicology in Vitro, 23(3):386-392.

39. Zheleva-Dimitrova D, Nedialkov P, Kitanov G (2010) Radical scavenging and antioxidant activities of methanolic extracts from Hypericum species growing in Bulgaria. Pharmacognosy magazine, 6(22):74.

40. Zheng J, He J, Ji B, Li Y, Zhang X (2007) Antihyperglycemic activity of Prunella vulgaris L. in streptozotocin- induced diabetic mice. Asia Pac. J. Clin. Nutr., 16(1):427-431. doi: 10.6133/apjen.2007.16.s1.78 